\title{
A ÉTICA NO SERVIÇO PÚBLICO
}

\author{
Suzy Elizabeth Cavalcante Koury'
}

\section{1- INTRODUÇÃO}

A Ética no Serviço Público é tema que reputo como dos mais relevantes na Administração Pública, pois só o exercício ético dos cargos e funções públicas é que contribuirá para que se alcance uma sociedade melhor.

Assim, visando desincumbir-me deste desiderato, analisarei a ética no serviço público, partindo de uma breve conceituação sobre ética e moral, para chegar à análise do princípio da moralidade em nosso ordenamento jurídico e das regras aplicáveis aos servidores públicos.

Finalmente, discorrerei sobre os sistemas de controle existentes, procurando sugerir medidas para o aperfeiçoamento do sistema vigente.

\section{2- ÉTICA: CONCEITUAÇÃO}

A palavra ética origina-se do grego ethos, significando Á modo de ser ou caráter, sendo conceituada por VÃZQUEZ" como "... a teoria ou ciência do comportamento moral dos homens em sociedade."

O objeto de estudo da ética é a moral, que se constitui de atos humanos conscientes e voluntários dos indivíduos que afetam outros indivíduos, grupos sociais ou a sociedade em seu conjunto.

Releva destacar que o conceito de ética é relativo, caracterizando-se por sua historicidade, de tal forma que as doutrinas éticas não podem ser consideradas isoladamente, mas dentro de um processo constante de mudança relacionado à própria evolução histórica da sociedade. ${ }^{3}$

1 A autora é Doutora em Direito pela UFMG, Procuradora do Estado do Pará e advogada.

2 VÁSQUEZ, Adolfo Sanchez. Ética, 18 ed., Rio de Janeiro, Civilização Brasileira, 1998, p.12.

3 Para um estudo aprofundando do tema, v. VÁSQUEZ, id. ibid., pp.24-46. 
Assim é que, a ÉTICA GREGA (Séc. V), que desenvolveu-se em um momento histórico de triunfo da democracia escravista sobre o domínio da velha aristocracia, relacionava-se, nos estudos de Sócrates, Platão e Aristóteles, com a existência de uma comunidade democrática limitada e local — o Estado-cidade ou pólis.

Já a ÉTICA CRISTÃ MEDIEVAL era TEOCÊNTRICA(Séc. IV), pois, surgida na época em que a escravidão cedeu lugar ao regime de servidão, refletia a relevância e à importância atribuídas à religião, que, apesar da fragmentação política e econômica, conseguia proporcionar alguma unidade, exercendo a Igreja poder espiritual e monopólio sobre a vida intelectual e sobre a moral efetiva vigente na sociedade.

No MUNDO MODERNO (Séc. XVI e início do Séc. XIX) vigorou a ÉTICA ANTROPOCÊNTRICA, que concebia o homem como seu centro e fundamento, considerando-o, de uma maneira abstrata, dotado de uma natureza universal e imutável, destacando-se KANT como um de seus principais idealizadores. Esta doutrina surgiu em um momento histórico caracterizado pelo fortalecimento de uma nova classe, a burguesia, a separação entre a Igreja e o Estado e o surgimento dos estados centralizados.

Finalmente, nos séculos XIX e XX, após a Revolução Francesa de 1789, época de progressos científicos e técnicos e de um grande desenvolvimento das forças produtoras, surgiu a ÉTICA CONTEMPORÂNEA, que reage contra o formalismo em favor de um homem concreto (existencialismo), contra o racionalismo absoluto em favor do reconhecimento do irracional no comportamento humano (pragmatismo, psicanálise) e contra a fundamentação transcendente da ética em favor da procura de sua origem no próprio homem.

É esse o momento histórico em que procedemos o estudo da Ética no Serviço Público, passando à análise da moral, seu objeto.

\section{3- MORAL E MORALIDADE}

A moral origina-se do latim mos ou mores, costume ou costumes, tendo o sentido de conjunto de normas ou regras adquiridas por hábito.

Desse modo, a moral é comumente conceituada como um conjunto de normas, aceitas de forma livre e consciente, que regulam o comportamento individual e social dos homens.

A moral em ação ou em prática faz surgir a moralidade, entendida como o "... conjunto de relações efetivas ou atos concretos que adquirem um significado moral com respeito à 'moral' vigente." 4

Do mesmo modo que a ética, a realidade moral caracteriza-se por sua historicidade e relatividade, ou seja, varia historicamente e, com ela, variam os seus princípios e as suas normas.

A moral tem, portanto, caráter mutável, modificando-se de acordo com a mudança e a transformação operadas nas sociedades concretas. 
Assim é que, a MORAL PRIMITIVA era COLETIVISTA, pois imposta pela necessidade de fortalecimento dos laços que uniam os membros da coletividade para que pudesse, unidos, enfrentar os perigos. Por esta razão, vigia nos limites da gens ou da tribo, de tal forma que, fora deles, seus princípios e suas normas perdiam a validade.

No Mundo Antigo, em que imperava a escravidão, a moral que dominava era a dos homens livres, sendo que os filósofos da antigüidade, como Aristóteles, justificavam a situação dos escravos utilizando-se do argumento de que alguns homens eram livres, e outros, escravos, por natureza, afirmando que esta distinção era útil e justa.

Na sociedade feudal, imperava, da mesma forma que no campo da ética, a moral religiosa, havendo também, em razão da grande estratificação social existente, uma pluralidade de Códigos Morais (o dos aristocratas, o das corporações de ofício etc.)

Nos Estados Centralizados, a economia era regida pela lei do máximo lucro, imperando, por isso, uma moral própria do capitalismo clássico, sendo o operário considerado como homem econômico, validando-se, assim, sua exploração.

Patente, pois, o caráter relativo da moral, estritamente vinculado ao momento histórico, o que também pode ser observado em relação ao tema por nós abordado, o que passamos a analisar.

\section{4- O PRINCÍPIO CONSTITUCIONAL DA MORALIDADE}

Dado o caráter relativo e histórico da ética e da moral, também em nosso ordenamento jurídico é possível perceber a evolução da ética em cada um dos momentos históricos, destacando ROCHA ${ }^{5}$ que, no Brasil Colônia, por exemplo, imperavam a ganância e a obtenção de benefícios particulares pela manipulação e pelo abuso de bens públicos, o que pode ser facilmente verificado nos estudos a respeito daquela época.

Com a Independência do Brasil, a situação modificou-se, tendo constado de nossa $1^{2}$ Constituição a rejeição do sistema a condutas anti-éticas de juízes e oficiais de justiça. ${ }^{6}$

O Brasil-República, por sua vez, caracterizou-se pela fragilidade dos comportamentos morais da Administração Pública, tendo RUI BARBOSA, reiteradas vezes, denunciado as condições precárias da ética no exercício do Poder no Brasil, com a prevalência de interesses de pessoas e de grupos, e não da coletividade. ${ }^{7}$

5 Cf. id. ibid., p. 216.

6 Art. 156 da Constituição do Império, de 1824: “" Todos os juízes de direito e os oficiais de justiça são responsáveis pelos abusos de poder e prevaricações que cometerem no exercício de seus empregos; esta responsabilidade se fará efetiva por lei regulamentar."

7 Cf. ROCHA, Carmen Lúcia Antunes. Princípios Constitucionais da Administração Pública, Belo Horizonte, Del Rey, 1994, p. 218. 
O Século XX trouxe uma forte tendência à juridicização das normas morais, a ponto de VICENTE RÁO referir-se a uma "moralização do Direito", nos seguintes termos:

"Se em todos os tempos se proclamou que o Direito, ao se concretizar em normas obrigatórias, há de respeitar os princípios da Moral, hoje mais do que nunca se acentua a tendência que as normas morais revelam no sentido de sua transformação em normas jurídicas; acentua-se, isto é, a tendência à moralização do Direito." 8

De fato, em todo o Século XX, e, de modo especial, na década de 90 , houve uma projeção da preocupação com a moralidade pública e a ética no serviço público, destacando CARMEN LÚCIA ANTUNES ROCHA que o novo liberalismo político, ao passar a imperar sozinho com a queda do Muro de Berlim, impôs esta valorização da ética em nossa sociedade, pois a liberdade e a justiça para todos, como princípios fundamentais da democracia, não poderiam ser asseguradas sem que fossem incluídas no ordenamento jurídico as normas morais.

Neste diapasão, a Constituição Federal de 1988, em seus artigos 5o, inciso LXXIII, 37, caput, e 85, inciso V, destacou a ética e elevou a moralidade a princípio constitucional da Administração Pública, de tal forma que todo e qualquer ato estatal passou a ter a ética como elemento indispensável à sua validade e eficácia, como destaca HELY LOPES MEIRELLES ${ }^{i 0}$.

Destaque-se que os princípios regedores da Administração Pública subordinam todo o sistema de normas, constitucionais ou infraconstitucionais, condicionando todo o ordenamento jurídico, a ponto de CELSO ANTÔNIO BANDEIRA DE MELLO afirmar que:

“|v|iolá-los implicará violação ao próprio Direito, configurando ilicitude que assujeita a conduta viciada a invalidação, porquanto tal princípio assumiu foros de pauta jurídica, na conformidade do art. 37 da Constituição." "

O conceito de moralidade administrativa foi sistematizado por HAURIOU, que a definiu como "...o conjunto de regras de conduta tiradas da disciplina interior da Administração" ${ }^{12}$, aduzindo que o agente administrativo deve distinguir entre o honesto e o desonesto, e não apenas entre o legal e o ilegal, pois a legalidade do ato administrativo é fiscalizada pela verificação da violação da lei, enquanto que a

8 Apud. ROCHA, id.ibid., p. 182.

9 Cf. id.ibid, pp. 175-6.

10 Cf. MEIRELLES, Hely Lopes. Direito Administrativo Brasileiro, $23^{2}$ ed., São Paulo, Malheiros, 1998 , p. 86.

11 BANDEIRA DE MELLO, Celso Antônio. Curso de Direito Administrativo, $11^{2}$ ed., São Paulo, Malheiros, 1999, pp. 72-3.

12 Apud. id. ibid., p. 86. 
conformidade deste ato à boa administração depende da verificação do desvio de poder, cuja zona de policiamento é a moralidade administrativa.

A partir da sistematização de HAURIOU, a moralidade administrativa passou a integrar a esfera jurídica, ensinando ANTONIO JOSÉ BRANDÃO ${ }^{13}$, em estudo sobre sua evolução, que foi no âmbito do Direito Civil que se iniciou sua incorporação ao Direito, inicialmente através da doutrina do exercício abusivo de direitos, e posteriormente, pelas doutrinas do não-locupletamento à custa alheia e da obrigação natural.

Na mesma ordem de idéias desenvolvida por HAURIOU, ROCHA conceitua a moralidade administrativa como:

“...o princípio segundo o qual o Estado define o desempenho da função administrativa segundo uma ordem ética acordada com os valores sociais prevalecentes e voltada à realização de seus fins." 14

A moralidade administrativa não se confunde com a moral comum, não sendo uma questão de opção para o servidor público, nem dizendo respeito à índole do ser humano, na medida em que se diferenciam os fins buscados pelo ser humano e os almejados pela Administração.

$\mathrm{Na}$ verdade, a moralidade administrativa está vinculada à supremacia do interesse público sobre o privado, sendo a corrupção sua negação, já que se baseia na indistinção do público e do privado, de tal forma que "... somente o interesse público legitima o comportamento da Administração Pública. E apenas a conduta administrativa legítima tem sede no Direito do Estado Democrático." 15

Do mesmo modo, a moralidade difere da legalidade, pois, como já destacava RADBRUCH $^{16}$, uma lei que contrarie os princípios básicos da moralidade não integra o Direito, ainda que seja formalmente válida. ${ }^{17}$

De fato, apesar de ter-se formado a partir do princípio da legalidade, para que se chegasse ao conceito de moralidade foi necessário acrescer-se a idéia de legitimidade do Direito, podendo-se afirmar que a Administração Pública deve ser ética para que seja juridicamente válida.

Como destaca HELY LOPES MEIRELLES, in verbis:

"Por considerações de Direito e de Moral, o ato administrativo não terá que obedecer somente à lei jurídica, mas também à lei ética da própria instituição,

13 BRANDÃO, Antonio José. Moralidade Administrativa. Revista de Direito Administrativo, São Paulo, 25: 454-67, p. 454.

14 Op. cit., p. 192.

15 Id. ibid., p. 214.

16 Apud. ROCHA, op. cit., p. 181.

17 Para uma análise da distinção entre os dois princípios à luz da CF/88, cf. DI PIETRO, Maria Sylvia Zanella. Direito Administrativo, $11^{2}$ ed., São Paulo, Atlas, 1999, p. 70. 
porque nem tudo que é legal é honesto, conforme já proclamavam os romanos: 'non omne quod licet honestum est'." (negrito) $)^{18}$

$\mathrm{Na}$ verdade, a moralidade administrativa encontra-se estritamente vinculada à idéia de legitimidade, a qual não é concebida senão em consonância com os padrões morais assentados socialmente.

Neste sentido, afirma CARMEM LÚCIA ANTUNES ROCHA, in verbis:

"A moralidade administrativa legitima o comportamento da Administração Pública, elaborada como ela é por um Direito nascido do próprio povo. Por isso, é o acatamento da moralidade administrativa, como princípio de Direito que dota o sistema de legitimidade..." 19

Em assim sendo, em um Estado Democrático de Direito, pode-se afirmar a primazia do princípio da moralidade sobre os demais princípios que regem a Administração Pública de tal forma que, em um eventual conflito entre, por exemplo, os princípios da moralidade e da legalidade, deve prevalecer o da moralidade.

Registre-se que HAURIOU, em 1927, já se referia ao fato de a "...moralidade administrativa ser ainda mais exigente que a legalidade." 20

Desta forma, a título de exemplificação, a possibilidade de membros dos Poderes Legislativo e Judiciário contratarem parentes para cargos em comissão viola o princípio da moralidade, dando ensejo, inclusive, a ações populares para que seja declarada sua inconstitucionalidade.

Destaque-se, por fim, que o princípio da moralidade está ligado à idéia de probidade, de tal forma que a conduta do administrador público em desrespeito a ele constitui ato de improbidade, sujeitando-o às sanções previstas no $\S 4^{\circ}$, do artigo 37, da CF/88, na Lei Federal nº 8.429/92 e, no Estado do Pará, na Lei Estadual no $5.844 / 94$.

Pode-se concluir que a Constituição Federal de 1988 proporcionou, por várias razões, o fortalecimento da cidadania e elevou a ética no serviço público a princípio conformador de toda a Administração Pública em nosso País, possibilitando, de forma mais eficaz, o seu controle e a sua defesa pelas instituições e pelos cidadãos.

\section{5- ÉTICA NO SERVIÇO PÚBLICO: NORMATIZAÇÃO E CONTROLE}

O fato de a Carta Federal de 1998 ter garantido assento constitucional à ética no serviço público, por si só, tornaria desnecessário, a rigor, que houvesse uma normatização a respeito.

18 Op. cit., p. 86.

19 Id. ibid., p. 191.

20 Apud. ROCHA, op. cit, p. 189. 
Todavia, continua havendo amplo debate acerca da necessidade de serem elaborados novos diplomas legais para garantir sua observância, fenômeno este que, como dá notícia CARMEN LÚCIA ROCHA ${ }^{21}$, também está ocorrendo em outros ordenamentos jurídicos, como o francês, o italiano e o português, dentre outros.

Esta situação é explicada pelo fato de, apesar dos avanços, e da existência de uma série de instrumentos de controle, ainda ser possível afirmar que nem sempre o interesse público prevalece sobre o privado em nosso País.

Em 1994, o Governo Federal fez editar um Código de Ética Profissional do Servidor Público Civil do Poder Executivo Federal, aprovado pelo Decreto $\mathrm{n}^{0} 1.171$, de 22 de junho de 1994, e que foi elaborado por uma Comissão Especial coordenada por MODESTO CARVALHOSA, então Presidente da Comissão de Ética da OABSP.

O Código foi divido em dois Capítulos, sendo que o primeiro elenca os princípios morais e éticos a serem observados pelo servidor, bem como as vedações, e o segundo trata da criação e do funcionamento de Comissões de Ética em todos os órgãos do Poder Executivo Federal.

Essas Comissões não têm poder de coerção, o que foi justificado pelo então Ministro da Administração Federal, ROMILDO CANHIN, pelo fato de não se tratar de mais uma lei, e sim de um Código de Ética, “... que deverá ser cumprido não tanto por sua condição de ato estatal, aprovado por um Decreto do Senhor Presidente da República, na qualidade de titular da 'direção superior da administração federal' (Constituição, artigo 84, inciso II), mas principalmente em virtude da adesão de cada servidor, em seu foro íntimo..", pois "... o princípio da obrigatoriedade do procedimento ético e moral no exercício da função pública não tem por fundamento a coercibilidade jurídica." 22

Após cerca de 6 (seis) anos de sua entrada em vigor, não se ouve falar nas Comissões de Ética, nem, tampouco, houve sucesso na tentativa de adesão espontânea ao procedimento ético, como se pode constatar da leitura diária dos jornais brasileiros, o que pode ser explicado pelo fato de ter o mesmo partido de premissa equivocada, qual seja, a de que a ética no serviço público se confundiria com a ética comum, e que não poderia ser juridicamente imposta, o que, como vimos, não corresponde à posição pacífica da doutrina e da jurisprudência.

Ao contrário. É cediço que a observância da ética e do princípio da moralidade na Administração Pública podem, e devem, ser impostos, havendo uma variedade de instrumentos de controle à disposição em nosso ordenamento jurídico.

Com efeito, o controle poder ser efetuado pela própria Administração, dentro de seu dever de apurar e punir todos os atos ilegais ou abusivos praticados pelos servidores públicos, com fundamento nas regras estatutárias (Lei 8.112/90, Estatuto do Servidor Público Federal, art. 116, inciso IX), que regem suas relações, assim

21 Id. ibid., p. 227.

22 CANHIN, Romildo. Exposição de Motivos. Código de Ética Profissional do Servidor Público Civil do Poder Executivo Federal. Brasília, ENAP, 1994, p.10. 
como no Código de Ética, sendo exercida, ainda, pelos órgãos de controle interno previstos no artigo 70 , da $\mathrm{CF} / 88$.

No que diz respeito aos advogados públicos, não há normas específicas, aplicando-se-lhes as normas gerais relativas aos demais servidores públicos, assim como Estatuto e o Código de Ética da OAB, destacando-se em relação aos mesmos a regra constante do seu artigo $4^{\circ}$, podendo recusar o patrocínio de pretensão concernente a lei ou direito que lhe seja aplicável, ou contrarie expressa manifestação sua, anteriormente feita.

Merece destaque, ainda, em relação aos advogados públicos, a regra contida no artigo 20 do Código de Ética da OAB, a saber:

"Art. 20. O advogado deve abster-se de patrocinar causa contrária à ética, à moral ou à validade de ato jurídico em que tenha colaborado, orientado ou conhecido em consulta; da mesma forma, deve declinar seu impedimento ético quando tenha sido convidado pela outra parte, se esta lhe houver revelado segredos ou obtido seu parecer."

Registre-se que a atuação disciplinar da OAB sobre os advogados públicos, em que pese deva levar em conta as peculiaridades éticas destes profissionais, como servidores públicos que são, é pacífica no que pertine a suas atuações como advogados, dentro do controle disciplinar que lhe é inerente e no mister de ver observado em sua plenitude o mandamento constitucional segundo o qual os advogados são indispensáveis à administração da Justiça. ${ }^{23}$

É exatamente neste sentido o posicionamento de NALINI, in verbis:

"A circunstância de orientar ou de representar judicialmente o Estado não retira ao procurador os seus compromissos éticos de advogado. Todos os cânones éticos voltados aos advogados têm também como destinatários os procuradores. Algumas singularidades éticas podem ser apontadas, entretanto." ${ }^{24}$

Dentre as peculiaridades éticas referidas, pode-se apontar:

a) as que envolvem a aceitação da causa, sendo assente que ao Procurador, na qualidade de representante judicial do Estado, não é dado recusar a defesa do ente público, ainda que tenha convicção de que não lhe assiste razão, caso em que deverá defendê-lo em Juízo, mas, internamente, esclarecer a seus superiores sobre os riscos de sucumbência na demanda e, em nome dos princípios constitucionais que regem

23 Para um amplo estudo sobre a ética profissional dos advogados públicos, v. FARIA, Dárcio Augusto Chaves. A Ética Profissional dos Procuradores Públicos. Revista de Direito da Procuradoria Geral, Rio de Janeiro, (46): 77-102, 1993, e MELO, Mônica de. Ética na Advocacia Pública. In: Livro de Teses do XXV Congresso Nacional dos Procuradores do Estado (25:1999: teses), Maceió, Procuradoria Geral do Estado, 1999, pp.453-66, p.464-5.

24 NALINI, José Renato. Ética Profissional e Geral, 2* ed., São Paulo, Revista dos Tribunais, 1999, p. 240. 
a Administração Pública, sugerir composição ou reconhecimento do Direito, tudo em nome do interesse público, procedimento este que encontra respaldo no artigo $8^{2}$, do Código de Ética da OAB.

Nos casos em que o ente público for autor, existindo manifesta ilegalidade ou imoralidade na pretensão a ser deduzida, pode haver a recusa lícita do advogado público, desta feita com fundamento no artigo 34, inciso VI, do Estatuto da OAB.

Deve-se destacar que a questão de aceitação da causa não envolve considerações sobre justiça ou injustiça, pois envolvem conceitos pessoais e relativos, casos em que o advogado público deve manifestar sua suspeição para atuar no feito.

b) uma outra peculiaridade é a que envolve a suspeição para a causa, podendo o advogado público argüi-la sempre que tenha interesse direto ou indireto no objeto da lide, no caso de já estar vinculado por pronunciamento contrário anterior acerca. da mesma questão, ou por ser parente ou amigo íntimo dos envolvidos na mesma.

c) destaque-se, ainda, a questão do segredo profissional, referida no artigo 20 do Código de Ética, acima transcrito, e da impossibilidade de os advogados públicos reconhecerem a procedência, confessarem, transigirem ou renunciarem ao direito em que se funda a ação, sem autorização por quem detenha poderes para tal, dado o caráter de indisponibilidade dos bens e do interesse público.

Exerce papel preponderante nestas questões o TRIBUNAL DE ÉTICA E DISCIPLINA (TED) DAS DIVERSAS SEÇÕES DA OAB, trazendo-se à colação algumas decisões tomadas pelo TED da OAB-SP ${ }^{25}$, em relação aos advogados públicos:

"O advogado ex-empregado ou ex-funcionário está impedido de atuar, como advogado, contra seu ex-empregador, durante dois anos após o seu desligamento de qualquer natureza, em razão não só de problemas de sigilo profissional, como também de familiaridade no trato das peculiaridades dos direitos patronais, impedimento esse que ultrapassa os dois anos, se ferir o sigilo profissional." (Proc. E- 1.496, v.u., Rel. Dr. GERALDO JOSÉ G. DA SILVA, rev. Dr. ELIAS FARAH, Presidente Dr. ROBINSON BARONI)."

“A possibilidade de patrocínio de ações, por ex-procurador municipal contra o Poder Público a que pertenceu, não atentará contra a ética profissional, desde que tenha transcorrido o prazo de dois anos do efetivo desligamento. $O$ conhecimento de documentos $\mathrm{e} o$ acesso a informações privilegiadas tornam indeterminado o impedimento, em face da regra do sigilo profissional, vedada, ainda, a postulação contra ato em que tenha tido participação."

(Proc. E-1.781/98, v. u., em 19.11.98, do parecer e ementa da Relatora Dra. ROSELI PRÍNCIPE THOMÉ, rev. Dr. BAISI ANTONIO RUGGIERO Presidente Dr. ROBINSON BARONI.)

No que diz respeito à fiscalização contábil, financeira, orçamentária, operacional e patrimonial, destaca-se o papel a ser desempenhado pelas Cortes de Contas, que 
podem representar por ilegalidades ou abusos de administradores, na forma do disposto no artigo 71, inciso XI, da Carta de 1988.

Os cidadãos, por sua vez, têm a seu dispor a Lei no 4.717/65, a Lei da Ação Popular, que, como destaca ROCHA ${ }^{26}$, constitui um dos melhores exemplos da possibilidade constitucional de sua participação no controle da qualidade ética dos comportamentos públicos, devendo-se destacar que MANOEL DE OLIVEIRA FRANCO SOBRI$\mathrm{NHO}^{27}$ sustenta, inclusive, a possibilidade de controle do princípio da moralidade, em caso concretos em que se possa falar de um direito líquido e certo à sua observância, até mesmo através de mandado de segurança.

Destaque-se, por fim, a atuação do Poder Judiciário, o qual, em diversas ocasiões, já invalidou atos administrativos por violação ao princípio da moralidade, como se depreende das seguintes decisões a seguir transcritas:

“Caracteriza ato lesivo à moralidade administrativa, passível de anulação no âmbito da ação popular, a alienação de lotes de terrenos pertencentes à municipalidade, contíguos a outros de propriedade do prefeito, e posteriormente por ele adquiridos, visto que a área contínua se valoriza quando agregada à primitiva. Tal fato evidencia interesse particular na alienação, caracterizando desvio de poder e não atendimento às finalidades do bem comum, às quais está adstrita a Administração."

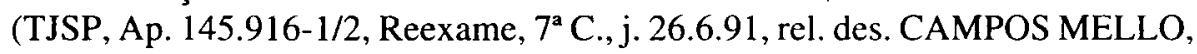
in Revista dos Tribunais, São Paulo, 673: 61-3, nov. 1991, p. 61.)

“JUIZ CLASSISTA. SUPLÊNCIA. VINCULAÇÃO. Na hipótese de afastamento do representante classista titular, há que ser convocado o suplente que com ele foi nomeado. $\mathrm{O}$ artigo 117 , caput e parágrafo único, da Constituição Federal merece interpretação calcada na razoabilidade, descabendo concluir estar nele encerrada a subjetividade, ou seja, a prerrogativa de o Presidente do Tribunal Regional do Trabalho vir, à livre discrição, pinçar o classista que substituirá o titular, olvidando os princípios da moralidade e impessoalidade e, sob o ângulo jurisdicional, o do juiz natural."

(STF, $2^{\mathrm{a}}$ T., RE 197888/BA, j. 13.01.97, Rel. Min. MARCO AURÉLIO, in DJU de 28.11 .97 , p. 62.231 .)

"I- Bacharel em Direito que exerce o cargo de assessor de desembargador: incompatibilidade para o exercício da advocacia. Lei 4.215, de 1963, artigos 83 e 84. Lei 8.906/94, art. 28, IV. Inocorrência de ofensa ao art. 50, XIII, que deve ser interpretado em consonância com o art. 22, XVI, da Constituição Federal, e comoprincípio da moralidade administrativa impostoà Administração Pública. (C. F, art. 37, caput).

26 Cf. op. cit., p. 222.

27 Cf. FRANCO SOBRINHO, Manoel de Oliveira. O Controle da Moralidade Administrativa, São Paulo, 1974, p.11. 
II- RE não conhecido."

(STF, $2^{\mathbf{a}}$ T., RE 199088/CE, Rel. Min. CARLOS VELlOSO, in DJU de 16.04.99, p. 024.)

Assim, percebe-se que há em nosso ordenamento jurídico instrumentos legais eficazes e suficientes para que se faça valer, efetivamente, a ética no serviço público.

\section{6- CONCLUSÃO}

Face às considerações até aqui desenvolvidas, pode-se concluir que:

a) a ética, ciência do comportamento moral dos homens em sociedade, e a moral, objeto de estudo da ética, caracterizam-se por sua historicidade e relatividade, variando seus princípios e normas com a própria evolução histórica da sociedade;

b) a década de 90 no Brasil destacou-se pela grande preocupação com a moralidade pública e a ética no serviço público, o que foi refletido pela Constituição Federal de 1988, a qual, em seus artigos 5o, inciso LXXIII, 37, caput, e 85, inciso V, destacou a ética e elevou a moralidade a princípio constitucional da Administração Pública;

c) a moral administrativa distingue-se da moral comum, pois está vinculada à supremacia do interesse público sobre o privado, constituindo a corrupção sua negação, vez que baseada na indistinção entre o público e o privado;

d) a moralidade difere da legalidade, pois "nem tudo que é legal é honesto", encontrando-se a moralidade administrativa vinculada à idéia de legitimidade, a qual não é concebida senão em consonância com os padrões morais assentados socialmente;

e) em um Estado Democrático de Direito, pode-se afirmar a primazia do princípio da moralidade sobre os demais princípios que regem a Administração Pública, de tal forma que, em um eventual conflito, deverá prevalecer;

f) a observância da ética e da moralidade no serviço público pode, e deve, ser imposta, havendo uma variedade de instrumentos de controle em nosso ordenamento jurídicos, controles este que precisam ser mais e melhor utilizados.

Por outro lado, dever-se-ia adotar algumas medidas para que seja assegurada a prevalência do interesse público sobre o privado, o triunfo da ética sobre a corrupção, sugerindo-se:

$1^{2}$ ) que o respeito ao Código de Ética integre o compromisso de posse de todos os servidores públicos;

$\left.2^{a}\right)$ que se combata a impunidade para que não se perca a fé nas instituições;

$\left.3^{a}\right)$ que se concentre esforços na educação e na conscientização ética da sociedade e, em particular, dos servidores públicos, restaurando-se a cidadania através da formação de cidadãos livres, críticos e que participem da definição dos destinos da Nação;

$\left.4^{a}\right)$ que se valorize os servidores públicos, através do pagamento de salários dignos, de sua qualificação e da definição de suas carreiras, garantindo-lhes estabilidade e profissionalização. 


\section{BIBLIOGRAFIA}

1- BANDEIRA DE MELLO, Celso Antônio. Curso de Direito Administrativo, $11^{\text {a }}$ ed., São Paulo, Malheiros, 1999, pp. 72-3.

2- BRANDÃO, Antonio José. Moralidade Administrativa. Revista de Direito Administrativo, São Paulo, 25: 454-67, p. 454.

3- CANHIN, Romildo. Exposição de Motivos. Código de Ética Profissional do Servidor Público Civil do Poder Executivo Federal. Brasília, ENAP, 1994, p.10.

4- DI PIETRO, Maria Sylvia Zanella. Direito Administrativo, $11^{2}$ ed., São Paulo, Atlas, 1999 , p. 70.

5- FARIA, Dárcio Augusto Chaves. A Ética Profissional dos Procuradores Públicos. Revista de Direito da Procuradoria Geral, Rio de Janeiro, (46): 77-102, 1993.

6- FRANCO SOBRINHO, Manoel de Oliveira. O Controle da Moralidade Administrativa, São Paulo, 1974, p.11.

7- MEIRELLES, Hely Lopes. Direito Administrativo Brasileiro, $23^{\mathrm{a}}$ ed., São Paulo, Malheiros, 1998, p. 86.

8- MELO, Mônica de. Ética na Advocacia Pública. In: Livro de Teses do XXV Congresso Nacional dos Procuradores do Estado (25:1999: teses), Maceió, Procuradoria Geral do Estado, 1999, pp.453-66.

9- NALINI, José Renato. Ética Profissional e Geral, $2^{a}$ ed., São Paulo, Revista dos Tribunais, 1999, p. 240.

10- ROCHA, Carmen Lúcia Antunes. Princípios Constitucionais da Administração Pública, Belo Horizonte, Del Rey, 1994, p. 218.

11- VÁSQUEZ, Adolfo Sanchez. Ética, 18 ed., Rio de Janeiro, Civilização Brasileira, 1998, p.12. 